\title{
Testosterone, cortisol, and serotonin as key regulators of social aggression: A review and theoretical perspective
}

\author{
Estrella R. Montoya $\cdot$ David Terburg • \\ Peter A. Bos $\cdot$ Jack van Honk
}

Published online: 25 November 2011

(C) The Author(s) 2011. This article is published with open access at Springerlink.com

\begin{abstract}
In human and non-human animals the steroid hormones cortisol and testosterone are involved in social aggression and recent studies suggest that these steroids might jointly regulate this behavior. It has been hypothesized that the imbalance between cortisol and testosterone levels is predictive for aggressive psychopathology, with high testosterone to cortisol ratio predisposing to a socially aggressive behavioral style. In this review, we focus on the effects of cortisol and testosterone on human social aggression, as well as on how they might modulate the aggression circuitry of the human brain. Recently, serotonin is hypothesized to differentiate between impulsive and instrumental aggression, and we will briefly review evidence on this hypothesis. The aim of this article is to provide a theoretical framework for the role of steroids and serotonin in impulsive social aggression in humans.
\end{abstract}

Keywords Testosterone $\cdot$ Cortisol $\cdot$ Serotonin · Impulsive aggression · Instrumental aggression

\section{Introduction}

The steroids cortisol (CRT) and testosterone ( $\mathrm{T}$ ) have become well-established targets in the search of hormonal modulators of social aggression. In the literature, aggression is commonly divided into an impulsive and

E. R. Montoya $(\bowtie)$ - D. Terburg · P. A. Bos · J. van Honk Department of Experimental Psychology, Utrecht University, Utrecht, The Netherlands

e-mail: E.R.Montoya@uu.nl

J. van Honk

Department of Psychiatry and Mental Health, University of Cape

Town, Cape Town, South Africa instrumental subtype. Impulsive aggression, also named reactive aggression, is unplanned and driven by affect. Instrumental aggression, also named proactive aggression, is premeditated and is characterized by a lack of emotions (Blair 2010). Recently, it has been suggested that the balance between $\mathrm{T}$ and CRT levels, that is the testosterone/ cortisol ratio (T/CRT), might be predictive for both types of aggression (Terburg et al. 2009; van Honk et al. 2010). Two decades ago, pioneering research of James Dabbs and his colleagues already forecasted this notion as they found relationships between CRT, $\mathrm{T}$ and aggression in a sample of 113 male offenders (Dabbs et al. 1991). A significant positive correlation was found between $\mathrm{T}$ and aggression, but interestingly, this effect was only evident in offenders with low CRT levels. In offenders with high CRT levels, the T-aggression relationship was not observed, which according to the authors could indicate that CRT is a "biological predictor of psychological variables (e.g., social withdrawal) that moderate the testosterone-behavior relationship" (Dabbs et al. 1991, p. 469). Indeed, CRT is strongly linked to social withdrawal, which is shown by many studies that will be discussed in this review. Recent studies have found similar relationships between T, CRT and aggressive behavior in clinical populations (children with conduct disorder and adults with psychopathy) as well as healthy humans (Glenn et al. 2011; Mehta et al. 2008; Mehta and Josephs 2010; Pajer et al. 2006; Popma et al. 2007).

Together, these data suggest an interaction between $\mathrm{T}$ and CRT in the regulation of social aggression. This interaction does however not distinguish between the impulsive and instrumental subtypes of aggression. Recently, it has been proposed that low levels of the neurotransmitter serotonin (5-Hydroxytryptamine; 5-HT), in combination with high T/CRT ratio facilitate the impulsive 
subtype of aggression in particular (Terburg et al. 2009; van Honk et al. 2010) as low 5-HT relates to impulsive behavior. Thus, a neurobiological profile of low CRT, and high T levels, together with low 5-HT would predispose to impulsive aggression.

In the remainder of this review, we shall first discuss the dual-hormone approach. Secondly, we will focus on the independent effects of $\mathrm{T}$ and CRT on socio-emotional behavior and how they might work in concert to facilitate social aggression. Thirdly, the effects of CRT and T on the neural circuitry of aggression will be discussed. Then, we shall review evidence that points to a role of 5-HT in setting the predispositions for impulsive, rather than for instrumental aggression. Finally, this will accumulate in a dual-hormone serotonergic perspective of social aggression. The goal of this review is thus to provide a theoretical framework for the study of neurobiological regulation of aggression.

\section{A dual-hormone approach in the study of social aggression}

As there is growing evidence that $\mathrm{T}$ and CRT together regulate social aggression, the question how this neurobiological mechanism operates becomes inevitable. CRT and $\mathrm{T}$ are the end products of the hypothalamic-pituitaryadrenal (HPA) and hypothalamic-pituitary-gonadal (HPG) axes, respectively. The HPA axis consists of three levels, beginning with the paraventricular nucleus $(\mathrm{PVN})$ of the hypothalamus, which produces corticotropin-releasing hormone $(\mathrm{CRH})$ in response to stress. $\mathrm{CRH}$, in turn, promotes the release of adrenocorticotropic hormone (ACTH) by the pituitary; the second level of the HPA axis. ACTH then stimulates the adrenal cortex, which ultimately leads to the synthesis and release of glucocorticoids (corticosterone in rodents and cortisol in humans). The HPG axis also consists of three levels of which the two first levels are the hypothalamus and the pituitary gland, where gonadotropinreleasing hormone $(\mathrm{GnRH})$ and luteinizing hormone $(\mathrm{LH})$ together with follicle stimulating hormone (FSH) are released respectively. LH and FSH are transported to the third level of the HPG axis, the gonads, where they are responsible for the production of $\mathrm{T}$, the end product of the HPG axis. Critically for explaining the apparent interplay of $\mathrm{T}$ and CRT in the studies described above (Dabbs et al. 1991; Glenn et al. 2011; Pajer et al. 2006; Popma et al. 2007), is evidence that the adrenal and gonadal systems interact antagonistically, that is the HPG axis inhibits the HPA axis and vice versa (Viau 2002). CRT inhibits HPG axis activity at all levels, and T inhibits HPA axis activity at the level of the hypothalamus (Johnson et al. 1992; Tilbrook et al. 2000; Viau 2002). Such an interaction would in itself bias the neurobiological profile toward imbalance, i.e. either high $\mathrm{T}$ and low CRT, or high CRT and low T. It is important to note here that due to differences in androgen production between females and males, the interaction of the HPG and HPA axes may be different between the sexes. This is because while in males androgen production mainly originates from the HPG axis, the relative contribution of the HPG axis on $\mathrm{T}$ secretion in females is lower, as approximately half of the androgen production comes from the adrenal cortex, the final component of the HPA axis (Burger 2002). Therefore, although the HPA and HPG axes have a mutual inhibitory relationship in both sexes, the magnitude of this relationship might be different between males and females.

The T/CRT ratio hypothesis (Terburg et al. 2009; van Honk et al. 2010) states that the predisposition for social aggression develops from such an imbalance of the hormones CRT and T. This imbalance is indicated by T/CRT ratio (T:CRT), in which a high ratio reflects high $\mathrm{T}$ levels in relation to CRT levels, and a low ratio reflects low $\mathrm{T}$ relative to CRT levels. These circulating steroids are suggested to exert long-term (genomic) influence on social aggression by up-regulating neuropeptide gene expression (van Honk et al. 2010). On the one hand, $\mathrm{T}$ elevates vasopressin gene expression at the amygdala, which facilitates aggressive approach (Schulkin 2003). Furthermore, $\mathrm{T}$ can regulate aggressive behavior by its conversion to estradiol (E) by the enzyme aromatase, which in rats promotes aggression [as discussed in (Trainor et al. 2006)]. On the other hand, excess of CRT and CRH promotes CRH gene expression in the amygdala, which facilitates fear/ anxiety and behavioral withdrawal (Schulkin 2007; Schulkin et al. 1998). As we shall see in the remainder of this review, these different action mechanisms at the amygdala seem to cause diametrically opposite effects at the behavioral level, influencing the way an individual will react aggressively (fight) or fearful (flight) in social confrontations.

\section{Effects of basal and exogenous cortisol and testosterone on social aggressive behavior}

Causal evidence for effects of CRT and $\mathrm{T}$ on social aggressive tendencies comes from hormone administration studies that utilize psychological paradigms, which index motives for aggressive approach and fearful withdrawal.

Steroids and the processing of facial threat

Human facial expressions are often used in these paradigms, because they convey socially relevant information by signaling anger or fear in the displayer (Wirth and 
Schultheiss 2007). Perceived facial fear signals indirect danger in the environment, while perceived facial anger signals direct threat towards the perceiver. The emotional Stroop task is a paradigm that is used to investigate attentional responses towards such emotional facial expressions (Williams et al. 1996). In this paradigm, colored facial expressions are shown and the participant is instructed to name the color of the face as fast as possible. It is assumed that longer response latencies reflect more interference of the emotional expressions, which is indicative for a vigilant response towards the facial expression, whereas faster color naming latencies point at an avoidant emotional response to the expression (van Honk et al. 1998, 1999).

Recently, in a new saccade-latency paradigm reminiscent of the emotional Stroop task, the validity of this interpretation was confirmed (Terburg et al. 2011). Gaze aversion away from angry faces was slower in subjects that scored high on Behavioral Activation System (BAS) scales that are linked to dominance and anger, suggesting a link between the vigilant response to angry faces found in emotional Stroop tasks and the aggressive staring-contest. In an earlier line of research by van Honk and coworkers it was shown that high salivary $\mathrm{T}$ levels are related to such vigilant responsiveness towards angry faces (van Honk et al. 1999), and avoidant responsiveness towards fearful faces (van Honk et al. 2005). These findings also were interpreted in terms of predispositions to react with aggression, and in terms of reductions in fear: These are characteristics that would together certainly predispose for social aggression. More important however is causal evidence provided by double blind, placebo-controlled, within-subject administration studies. These studies are in line with the correlative work, showing that autonomic responding (heart rate) to angry faces increases (van Honk et al. 2001), while autonomic responding to fear (fearpotentiated startle, i.e. a widely used laboratory model of fear) decreases following $\mathrm{T}$ administration (Hermans et al. 2006). Moreover, attentional measures of threat processing are affected in the same manner by $\mathrm{T}$ administration, as administration of $\mathrm{T}$ reduced biased attention towards fearful faces in females on a masked Stroop task (van Honk et al. 2005). Together, these studies extend the findings on autonomic responding towards threat after $\mathrm{T}$ administration and suggest that when $\mathrm{T}$ is high, autonomic and attentional vigilance towards facial anger cues increases while it decreases towards facial signs of fear. Importantly, while vigilance toward angry social cues might facilitate aggression, reduced fear sensitivity can have the same effect, because seeing fear in a victim normally attenuates aggression (Blair 1995, 2001).

Interestingly, the relationship between basal CRT levels and responding to angry faces is opposite to what is observed with basal $\mathrm{T}$ levels. While high basal levels of $\mathrm{T}$ are related to approach responses towards angry faces, it has been repeatedly shown that higher basal levels of CRT are associated with an avoidant response to angry faces (Putman et al. 2004; van Honk et al. 1998, 2000), fearful withdrawal, and reduced aggression (Böhnke et al. 2010; Hawes et al. 2009).

Studies using acute CRT administration however show an entirely different picture. For instance, whereas high basal CRT levels are related to inhibition of aggression, acute administration of glucocorticoids stimulates aggression (in rodents) (Hayden-Hixson and Ferris 1991). This paradox could be explained by the negative feedback-loop mechanism that is initiated in case of elevated glucocorticoid levels. Namely, one of the important functions of CRT is to restrain HPA axis activity, a process that occurs rapidly and profoundly [as discussed in (Schulkin et al. 1998)]. Although the HPA-axis produces CRT, and is active in case of fear, circulating CRT suppresses activity at all levels of the HPA-axis (Cassano and D'mello 2001; Ratka et al. 1989; Reul and de Kloet 1985). High basal levels of CRT are therefore a marker for fear, but their acute effect is to reduce fear. Placebo-controlled, withinsubjects administration studies show that acute effects of exogenous CRT are fear reducing. For example, Buchanan et al. (2001) showed that administration of hydrocortisone decreased the defensive acoustic startle reflex. Furthermore, similar to what is observed after $\mathrm{T}$ administration, processing of fearful faces as assessed with the masked Stroop task is also affected (Putman et al. 2007a). Subsequent studies show similar fear reducing effects of CRT administration on threatening stimuli (Oei et al. 2009; Putman et al. 2010a; van Peer et al. 2010).

So there is abundant evidence that CRT administration is fear reducing. Here, it must also be noted that one study showed increased cognitive processing of anger after exogenous CRT (Putman et al. 2007b). This finding raises the question if CRT affects threat processing in general or specifically affects fear-processing. More studies must be conducted before we can answer this question.

In terms of social aggression, the above described studies overall suggest that the combination of high endogenous $\mathrm{T}$ and low endogenous CRT levels will lead to a heightened proneness for social aggression. A closer look at the psychological effects shows that exogenous $\mathrm{T}$ taps into anger as well as fear, as $\mathrm{T}$ increases approach and decreases avoidance motivation. The effects of exogenous CRT on the other hand, particularly tap into anxiety as basal CRT is an index of fearful withdrawal and exogenous application lowers fearful withdrawal. So although exogenous T and CRT will both facilitate aggressive approach, the underlying psychological mechanisms may be quite different. 
Steroids and decision-making

Thus far, this review focused on effects of T and CRT on early cognitive emotional processing such as in the emotional Stroop task, and on autonomic effects such as the startle reflex. These are laboratory measures that are difficult to translate to complex real-world behaviors such as decision-making. Social-economic decision-making paradigms allow easier translation to real-world social behavior and provide for a fruitful décor in which hormone effects can be studied. Paradigms such as the Iowa Gambling Task (Bechara et al. 1994), and the Ultimatum Game (Guth et al. 1982) for example, study the balance between punishment and reward sensitivity, which is directly related to aggression. Aggression is accompanied with a high reward-drive and low punishment sensitivity, prototypically seen in the psychopath (Arnett 1997; Raine 1996). Fearfulness, on the other hand, is associated with high punishment and low reward sensitivity (Arnett 1997). Not surprisingly, a hormonal profile of high $\mathrm{T}$ together with low CRT levels is related to a risky decision-making strategy on the Iowa Gambling Task, aimed at getting fast rewards irrespective of consequences that can involve punishment (van Honk et al. 2003, 2004).

In convergence, using a motivated decision-making task, Putman et al. (2010b) showed that CRT administration increased risky decision-making in males, reflected in a less punishment-sensitive decision-making strategy in comparison with the placebo condition. Moreover, risky decisions occurred when such decisions could potentially yield a big reward, reflecting heightened reward sensitivity. These studies again illustrate the contrasting effects of basal CRT and administration of CRT.

Another famous paradigm for investigating social-economic decision-making is the Ultimatum Game. This paradigm brings in a social aspect in decision-making because participants play against other people, creating a socially interactive environment. On each round in this game, the participant is endowed with an amount of money that has to be shared with the other player. The participant thus offers a part of his money to the other player, which the other player can either accept or reject. When making an unfair offer, the chance that the other player accepts reduces and rejection means money loss for both players. Following administration of T, men's proportion of fair offers on the Ultimatum Game decrease: they keep more money to themselves (Zak et al. 2009). So at first sight, exogenous $T$ seems to increase an anti-social, aggressive decision-making strategy. However, another study by Eisenegger et al. (2010) has provided us with a different perspective on the effects of $\mathrm{T}$ on socialeconomic decision-making. In this study, 60 women were given $\mathrm{T}$ or a placebo and had to play the proposer-role on the Ultimatum Game. Interestingly, when participants believed that they had received $\mathrm{T}$, they made more unfair offers, which is in line with the study of Zak et al. (2009). However, on top of this belief effect, the actual $\mathrm{T}$ administration effect was completely reversed. Instead of proposing less fair offers, women made more fair offers following $\mathrm{T}$ administration. The authors argue that their data is in favor of the 'status hypothesis', that predicts that $\mathrm{T}$ will not lead to antisocial behavior, but to behavior aimed at getting high social status, which in fact is promoted by making high offers as this will prevent a social conflict and thus a low rejection probability (Eisenegger et al. 2010). So, T might increase prosocial behavior because such behavior is instrumental in preventing social rejection. Although this is in conflict with the study of Zak et al. (2009), they did not account for the 'belief-effect' and included different sexes, which might explain their opposing results. When looking at responder behavior on the Ultimatum Game, high $\mathrm{T}$ levels predict high rejection rates in males and females (Burnham 2007; Mehta and Beer 2010), which is argued to be indicative of social aggression (Mehta and Beer 2010). But the one study that used administration of $\mathrm{T}$ found no effect on responder behavior in women and also did not find a relation between basal $\mathrm{T}$ levels and responder behavior (Eisenegger et al. 2010). Thus, while in males high $\mathrm{T}$ is related to social-economic decisions that could reflect a heightened aggressive approach drive fuelled by $\mathrm{T}$, in women this relationship is not confirmed and actually seems to be reversed (Eisenegger et al. 2010). Future administration studies should include males and females in an identical study design to investigate if there is a gender effect on how $\mathrm{T}$ administration affects social-economic decision-making.

Unfortunately, CRT administration effects are not yet studied within these two paradigms. Thus, in individuals with high $\mathrm{T}$ and low CRT levels reward-driven decision-making strategy is promoted, at least in a non-social context such as the Iowa Gambling Task. Reward sensitivity promotes aggression, and thus these data support the notion that high $\mathrm{T}$, together with low CRT promotes aggressive approach.

\section{Steroid effects on neural circuitry underlying aggression}

Besides the genomic effects that were discussed earlier (Schulkin 2003, 2007; Schulkin et al. 1998), animal studies have shown that CRT and $\mathrm{T}$ administration have direct effects on the excitability of neurons within the amygdala (Karst et al. 2010; Sarkey et al. 2008). With functional neuroimaging it is possible to gain insights about the neural mechanisms by which these steroids alter aggression circuitry in the human brain. Starting with T effects, Hermans et al. (2008) used functional Magnetic Resonance Imaging (fMRI) to investigate this issue. These researchers showed participants angry facial expressions to probe the reactive 
aggression circuitry of the brain consisting of the hypothalamus, amygdala, orbital frontal cortices (OFC) and periaqueductal grey (PAG) in the brainstem [for a review on the neuroanatomy of the aggression system see (Nelson and Trainor 2007)]. It was found that exogenous $T$ increased neural responses towards angry faces within this network. The amygdala is a key structure in the signaling of threat stimuli such as the angry and fearful face, and is supposed to regulate the processing thereof (Phelps and LeDoux 2005). Furthermore, amygdala and hypothalamus are known to have a rich androgen receptor distribution in animals (Sarkey et al. 2008), which supports the notion that this network is under strong mediation of T. Interestingly, in the study of Hermans and colleagues, T/CRT ratio correlated positively with activity in the amygdala-hypothalamus-PAG aggression network (Hermans et al. 2008). Recent correlative work is in line with this, showing that activity in amygdala in response to fearful and angry faces is positively correlated to serum and salivary $\mathrm{T}$ concentrations (Derntl et al. 2009; Manuck et al. 2010).

Turning to functional neuroimaging studies with CRT administration, similar paradigms have been conducted as with $\mathrm{T}$ administration. However, it seems that while $\mathrm{T}$ sensitizes the amygdala selectively towards angry faces, exogenous CRT seems to dampen amygdala reactivity in general. A recent study of Henckens et al. (2010) showed that acute hydrocortisone reduced left amygdala reactivity toward both fearful and happy faces. Desensitization of the amygdala in the resting brain following hydrocortisone administration has also been reported (Lovallo et al. 2010) and could explain the anxiolytic effects found in the administration behavioral studies (Buchanan et al. 2001; Putman et al. 2007a, b; van Peer et al. 2010). It remains to be scrutinized if CRT administration could alter amygdala responses selectively towards angry faces as to the best of our knowledge no fMRI study with CRT administration has included angry faces yet.

In sum, acute exogenous CRT reduces amygdala-mediated emotional processing, while acute exogenous $\mathrm{T}$ increases amygdala-mediated anger processing. When translating these findings towards the behavioral findings, it seems that $\mathrm{T}$ promotes vigilant responses to angry faces through inducing amygdala-hyperreactivity for angry faces and that exogenous CRT is anxiolytic, probably through inducing desensitization of the amygdala towards threat (fearful faces). What remains to be scrutinized, is which neural mechanisms are responsible for $\mathrm{T}$ effects on fearful faces and CRT effects on angry faces.

As discussed earlier in this review, CRT and T affect decision-making. The parameter within these paradigms that is manipulated by hormone administration is reward versus punishment sensitivity. To date, only one study examined neural responses towards reward following steroid administration. With fMRI and a reward anticipation task, Hermans et al. (2010) studied the effect of exogenous $\mathrm{T}$ on the neural circuitry implicated in reward anticipation. Behavioral studies previously showed that exogenous $\mathrm{T}$ was related to a reward-driven decisionmaking strategy (van Honk et al. 2004). Hermans et al. (2010) showed that administration of $T$ increased the neural response in ventral striatum, the 'reward network' of the brain, during the expectation of reward on a monetary incentive delay task. Hyperreactivity of this reward network following exogenous $\mathrm{T}$ could well explain the increased reward sensitivity observed on the behavioral paradigms following $\mathrm{T}$ administration. A neurobiological mechanism that could be involved in this T-reward link is the dopamine system. Androgens are known to modify the activity of dopaminergic neurons, which regulate the reward network, as are glucocorticoids [for a review on androgens, see (Wood 2008); for a review on glucocorticoids, see (Piazza and Le Moal 1997)]. Adrenal, as well as gonadal systems might thus interact with the brain's mesolimbic reward system to exert their effects on reward behavior.

In sum, exogenous $\mathrm{T}$ seems to induce hyperreactivity of neural circuitry involved in aggression and reward, while exogenous CRT seems to dampen neural responses towards fearful faces. A field that warrants further investigation is how $\mathrm{T}$ and CRT interact with the dopaminergic system to influence reward-sensitivity.

\section{Low serotonin and impulsive aggression}

Serotonin's role in impulsivity is well-established (Bevilacqua et al. 2010; Virkunnen and Linnoila 1993), and it is therefore a likely candidate to differentiate between impulsive and instrumental aggression in a person that already is prone to social aggression. Low 5-HT is related to impulsivity (Bevilacqua et al. 2010; Virkunnen and Linnoila 1993), and a large body of animal literature suggests that 5-HT is also causally involved in aggression. The majority of these studies suggest an inhibitory effect of 5-HT on aggression (Carrillo et al. 2009; Francesco Ferrari et al. 2005; Huber et al. 1997). Thus low 5-HT is related to impulsivity and aggression, leading to the hypothesis that high T/CRT ratio, in combination with low 5-HT facilitates impulsive aggression in particular (Terburg et al. 2009; van Honk et al. 2010). Indeed, low levels of the 5-HT metabolite 5-Hydroxyindoleacetic acid have been reported in males with antisocial personality traits and impulsive aggression (Linnoila et al. 1983; Soderstrom et al. 2001). Another study used the serotonin-releasing agent fenfluramine (Siever et al. 1999), which increases glucose metabolism in the OFC and cingulate cortices of healthy subjects, 
brain regions that are implied in the inhibition of impulsive aggression (Blair 2004). In impulsive aggressive males (intermittent explosive disorder), fenfluramine did not alter glucose metabolism in these brain regions, indicative of reduced 5-HT modulation (Siever et al. 1999). In line with this, a more recent study showed reduced 5-HT transporter availability in the anterior cingulate cortex (ACC) in impulsive aggressive males (Frankle et al. 2005). In females, the same relationship between low 5-HT and impulsive aggression in patient groups has been reported (Rosell et al. 2010). Overall, correlative human data does support the notion that 5-HT transmission, in prefrontal regions $\mathrm{OFC}$ and $\mathrm{ACC}$, is attenuated in impulsive aggressive individuals. Causal data is scarce, but in line with the above. A study that experimentally lowered and elevated 5-HT via tryptophan depletion and enhancement found that high trait, but not low trait aggressive males changed their behavior on the Taylor paradigm (Cleare and Bond 1995): a widely used aggression paradigm (Taylor 1967). Following tryptophan depletion high trait-aggressive subjects behaved more aggressive than following tryptophan enhancement (Cleare and Bond 1995). Another study illustrated that 5-HT enhancement led to a decrease in rejections on the Ultimatum Game and increased morality on moral scenario decision-making in males and females (Cima and Raine 2009; Crockett et al. 2010). Finally, a study by Crockett and colleagues showed that tryptophan depletion led to higher rejection rates on the Ultimatum Game in males and females (Crockett et al. 2008). Thus, while low 5-HT is related to impulsive aggression, high 5-HT is related to increased moral and prosocial behavior. In combination with a T/CRT induced aggression predisposition however, high 5-HT could lead to an instrumental aggressive style. The hypothesis that high 5-HT levels would accompany instrumental aggression however is purely speculative and needs to be investigated. However, a remarkable pattern in the literature on low 5-HT transmission and aggression is that the majority of these studies include patients with antisocial personality disorder and not patients with psychopathy, the latter being defined more profoundly by instrumental aggression (Cima and Raine 2009).

In sum, we propose that the T/CRT ratio modulates the biobehavioral balance between aggression and fear, and that in individuals with high T/CRT ratio, who thus have an aggressive disposition, low 5-HT induces impulsive aggression.

\section{A dual-hormone serotonergic hypothesis of impulsive aggression}

We have reviewed evidence suggesting that high $\mathrm{T}$ together with low CRT predisposes toward social aggression and that 5-HT could modulate the balance between impulsive and instrumental aggression. There are very few studies on aggression that take T, CRT and 5-HT into account simultaneously. One study by Kuepper et al. (2010) used a S-citalopram challenge, which increases 5-HT, to assess 5-HT availability in relation to T levels and self-reported measures of aggression. S-citalopram induces CRT release and therefore CRT response was measured as indicator of responsiveness to S-citalopram (Kuepper et al. 2010), nicely illustrating the tight positive relationship between 5-HT function and CRT. The authors however found that 5-HT availability and T levels were unrelated in males and females. Interestingly, an interaction was found between 5-HT, T, and aggression. Males, and not females, with low 5-HT availability and high $\mathrm{T}$ levels reported higher levels of aggression. This is the only study showing this interaction thus it needs to be replicated and investigated in females. Nonetheless, the study of Kuepper et al. (2010) does suggest that the combination of high $\mathrm{T}$ levels together with low 5-HT function facilitates aggression. This is in line with earlier work showing positive effects of high $\mathrm{T}$ levels together with low 5-HT function on impulsive aggression (Higley et al. 1996). This is an interesting finding because although there is evidence from the animal literature that T affects 5-HT function (Fink et al. 1999), correlations between $\mathrm{T}$ and cerebrospinal fluid or plasma 5-HT levels in humans are not found (Kuepper et al. 2010). However animal research also suggests that $\mathrm{T}$ does have an effect on 5-HT function, but via aromatization to E (Fink et al. 1999). More research needs to be done to elucidate the relationship between $\mathrm{T}$ and 5-HT function in humans, but it is clear that an imbalance in levels of these chemicals could potentiate impulsive aggression.

Together, these findings give rise to a dual-hormone serotonergic (DHS) hypothesis in which high T/CRT ratio predisposes to aggression in general, and low prefrontal 5-HT transmission, through promoting impulsivity and lowering fear, predisposes to impulsive aggression (see Fig. 1). In terms of neural mechanism, such a neurobiological profile enhances reactivity of the neurocircuitry of reactive aggression of which the key structure is the amygdala. Indeed, high T/CRT ratio is positively correlated with activity in the amygdala-hypothalamus-PAG aggression system in response to threat (Hermans et al. 2008). Furthermore, low 5-HT transmission in prefrontal cortex (PFC) might be related to reduced inhibitory prefrontal control over this reactive aggression network, leading to hyper-responsiveness. Indeed, impulsive aggressive patients have reduced amygdala-PFC connectivity (Decety et al. 2009; Marsh et al. 2008). Neuroimaging studies are also in line with this, showing that the impulsive aggressive individual is characterized by amygdala hyper-responsiveness, while the instrumental aggressive individual shows amygdala hyporesponsiveness towards threat (Blair 2010). Finally, gender 


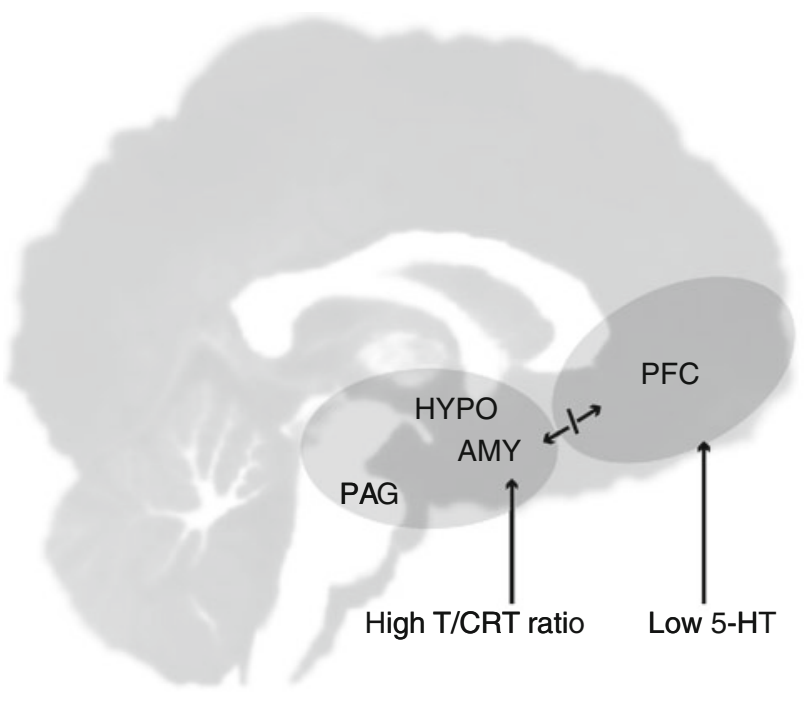

Fig. 1 Schematic overview of a dual-hormone serotonergic perspective on human impulsive aggression. High testosterone/cortisol (T/CRT) ratio acts on the amygdala to increase reactivity of the amygdala-hypothalamus-PAG network, which facilitates a fightresponse when confronted with social threat. Low 5-HT decreases prefrontal cortex (PFC) inhibitory control over the amygdalahypothalamus-PAG network, via reduced amygdala-PFC connectivity, thereby boosting impulsive aggression

differences in T levels, and their relation to 5-HT transmission should be studied further, but the antagonistic properties of $\mathrm{T}$ and CRT, as well as the relation between 5-HT and impulsivity are reliably observed in both sexes. Our dualhormone serotonergic hypothesis with high T, low CRT, and low 5-HT transmission, provides therefore a plausible framework for the study of impulsive aggression in both men and women.

\section{Conclusion}

The steroids CRT and $\mathrm{T}$ are in humans involved in social aggression, as the processing of social cues of threat is related to endogenous hormone levels and is altered by administration of these hormones. The effects of these hormones seem to tap into aggressive approach and fearful withdrawal, of which $\mathrm{T}$ and CRT are the hormonal equivalents respectively. Moreover, these effects also extend toward real-world behavior such as social-economic decision-making. A third important player in the neurobiological modulation of social aggression is 5-HT, which distinguishes between impulsive and instrumental aggression. Therefore the field of social neuroscience should broaden its scope to tackle the effects of this neurotransmitter in aggressionrelated paradigms. As we have reviewed, the levels of CRT, $\mathrm{T}$ and 5-HT are predictors of pathological aggression. Insights in these predictors can have implications for the treatment of clinically aggressive individuals. Future research on neurobiological mechanisms of social aggression should therefore further test the DHS hypothesis and take T/CRT ratio plus correlates of 5-HT function, such as 5-HT metabolites and genes, into account.

Acknowledgments This research was supported by a Netherlands Organization of Scientific Research Brain and Cognition Grant 056-24-010.

Open Access This article is distributed under the terms of the Creative Commons Attribution Noncommercial License which permits any noncommercial use, distribution, and reproduction in any medium, provided the original author(s) and source are credited.

\section{References}

Arnett, P. A. (1997). Autonomic responsivity in psychopaths: A critical review and theoretical proposal. Clinical Psychology Review, 17(8), 903-936.

Bechara, A., Damasio, A. R., Damasio, H., \& Anderson, S. W. (1994). Insensitivity to future consequences following damage to human prefrontal cortex. Cognition, 50, 7-15.

Bevilacqua, L., Doly, S., Kaprio, J., Yuan, Q., Tikkanen, R., Paunio, T., et al. (2010). A population-specific HTR2B stop codon predisposes to severe impulsivity. Nature, 468(7327), 1061-1066.

Blair, R. J. R. (1995). A cognitive developmental approach to morality: Investigating the psychopath. Cognition, 57, 1-29.

Blair, R. J. R. (2001). Neurocognitive models of aggression, the antisocial personality disorders, and psychopathy. Journal of Neurology, Neurosurgery and Psychiatry, 71, 727-731.

Blair, R. J. R. (2004). The roles of orbital frontal cortex in the modulation of antisocial behavior. Brain and Cognition, 55(1), 198-208.

Blair, R. J. R. (2010). Neuroimaging of psychopathy and antisocial behavior: A targeted review. Current Psychiatry Reports, 12(1), 76-82.

Böhnke, R., Bertsch, K., Kruk, M. R., \& Naumann, E. (2010). The relationship between basal and acute HPA axis activity and aggressive behavior in adults. Journal of Neural Transmission, 117(5), 629-637.

Buchanan, T. W., Brechtel, A., Sollers, J. J., \& Lovallo, W. R. (2001). Exogenous cortisol exerts effects on the strartle reflex independent of emotional modulation. Pharmacology, Biochemistry and Behavior, 68, 203-210.

Burger, H. G. (2002). Androgen production in women. Fertility and Sterility, 77(4).

Burnham, T. C. (2007). High-testosterone men reject low ultimatum game offers. Proceedings of the Royal Society B: Biological Sciences, 274(1623), 2327-2330.

Carrillo, M., Ricci, L. A., Coppersmith, G. A., \& Melloni, R. H. (2009). The effect of increased serotonergic neurotransmission on aggression: A critical meta-analytical review of preclinical studies. Psychopharmacology, 205(3), 349-368.

Cassano, W. J., \& D'mello, A. P. (2001). Acute stress-induced facilitation of the hypothalamic-pituitary-adrenal axis: Evidence for the roles of stressor duration and serotonin. Neuroendocrinology, 74, 167-177.

Cima, M., \& Raine, A. (2009). Distinct characteristics of psychopathy relate to different subtypes of aggression. Personality and Individual Differences, 47(8), 835-840.

Cleare, A. J., \& Bond, A. J. (1995). The effect of tryptophan depletion and enhancement on subjective and behavioural aggression in normal male subjects. Psychopharmacology, 118, 72-81. 
Crockett, M. J., Clark, L., Hauser, M. D., \& Robbins, T. W. (2010). Serotonin selectively influences moral judgment and behavior through effects on harm aversion. Proceedings of the National Academy of Sciences of the United States of America, 107(40), 17433-17438.

Crockett, M. J., Clark, L., Tabibnia, G., Lieberman, M. D., \& Robbins, T. W. (2008). Serotonin modulates behavioral reactions to unfairness. Science, 320, 1739.

Dabbs, J., Jurkovic, G. J., \& Frady, R. L. (1991). Salivary testosterone and cortisol among late adolescent offenders. Journal of Abnormal Child Psychology, 19(4), 469-478.

Decety, J., Michalska, K. J., Akitsuki, Y., \& Lahey, B. B. (2009). Atypical empathic responses in adolescents with aggressive conduct disorder: A functional MRI investigation. Biological Psychology, 80(2), 203-211.

Derntl, B., Windischberger, C., Robinson, S., Kryspin-Exner, I., Gur, R. C., Moser, E., et al. (2009). Amygdala activity to fear and anger in healthy young males is associated with testosterone. Psychoneuroendocrinology, 34(5), 687-693.

Eisenegger, C., Naef, M., Snozzi, R., Heinrichs, M., \& Fehr, E. (2010). Prejudice and truth about the effect of testosterone on human bargaining behaviour. Nature, 463(7279), 356-359.

Fink, G., Sumner, B., Rosie, R., Wilson, H., \& McQueen, J. (1999). Androgen actions on central serotonin neurotransmission: relevance for mood, mental state and memory. Behavioural Brain Research, 105, 53-68.

Francesco Ferrari, P., Palanza, P., Parmigiani, S., Dealmeida, R., \& Miczek, K. (2005). Serotonin and aggressive behavior in rodents and nonhuman primates: Predispositions and plasticity. European Journal of Pharmacology, 526(1-3), 259-273.

Frankle, W. G., Lombardo, I., New, A. S., Goodman, M., Talbot, P. S., Huang, Y., et al. (2005). Brain serotonin transporter distribution in subjects with impulsive aggressivity: A positron emission study with $[11 \mathrm{C}] \mathrm{McN}$ 5652. American Journal of Psychiatry, 162, 915-923.

Glenn, A., Raine, A., Schug, R. A., Gao, Y., \& Granger, D. A. (2011). Increased testosterone-to-cortisol ratio in psychopathy. Journal of Abnormal Psychology, 120(2), 389-399.

Guth, W., Schmittberger, R., \& Schwarze, B. (1982). An experimental analyses of ultimatum bargaining. Journal of Economic Behavior \& Organization, 3, 367-388.

Hawes, D. J., Brennan, J., \& Dadds, M. R. (2009). Cortisol, callousunemotional traits, and pathways to antisocial behavior. Current opinion in psychiatry, 22(4), 357-362.

Hayden-Hixson, D. M., \& Ferris, C. F. (1991). Steroid-specific regulation of agonistic responding in the anterior hypothalamus of male hamsters. Physiology \& Behavior, 50, 793-799.

Henckens, M. J., van Wingen, G. A., Joels, M., \& Fernandez, G. (2010). Time-dependent effects of corticosteroids on human amygdala processing. The Journal of Neuroscience: The Official Journal of the Society for Neuroscience, 30(38), 12725-12732.

Hermans, E. J., Bos, P. A., Ossewaarde, L., Ramsey, N. F., Fernández, G., \& van Honk, J. (2010). Effects of exogenous testosterone on the ventral striatal BOLD response during reward anticipation in healthy women. NeuroImage, 52(1), 277-283.

Hermans, E. J., Putman, P., Baas, J., Koppeschaar, H., \& van Honk, J. (2006). A single administration of testosterone reduces fearpotentiated startle in humans. Biological Psychiatry, 59(9), 872-874.

Hermans, E. J., Ramsey, N., \& van Honk, J. (2008). Exogenous testosterone enhances responsiveness to social threat in the neural circuitry of social aggression in humans. Biological Psychiatry, 63(3), 263-270.

Higley, J. D., Mehlman, P. T., Poland, R. E., Taub, D. M., Vickers, J., Suomi, S. J., et al. (1996). CSF testosterone and 5-HIAA correlate with different types of aggressive behaviors. Biological Psychiatry, 40, 1067-1082.
Huber, R., Smith, K., Isaksson, K., \& Kravitz, E. A. (1997). Serotonin and aggressive motivation in crustaceans: Altering the decision to retreat. Proceedings of the National Academy of Sciences, 94, $5939-5942$.

Johnson, E. O., Kamilaris, T. C., Chrousos, G. P., \& Gold, P. W. (1992). Mechanisms of stress: A dynamic overview of hormonal and behavioral homeostasis. Neuroscience and Biobehavioral Reviews, 16, 115-130.

Karst, H., Berger, S., Erdmann, G., Schutz, G., \& Joëls, M. (2010). Metaplasticity of amygdalar responses to the stress hormone corticosterone. Proceedings of the National Academy of Sciences, 107(32), 14449-14454.

Kuepper, Y., Alexander, N., Osinsky, R., Mueller, E., Schmitz, A., Netter, P., et al. (2010). Aggression-interactions of serotonin and testosterone in healthy men and women. Behavioural Brain Research, 206(1), 93-100.

Linnoila, M., Virkkunen, M., Scheinin, M., Nuutila, A., Rimon, R., \& Goodwin, F. K. (1983). Low cerebrospinal fluid 5-Hydroxyindoleacetic acid concentration differentiates impulsive from nonimpulsive violent behavior. Life Sciences, 33(26), 2609-2614.

Lovallo, W. R., Robinson, J. L., Glahn, D. C., \& Fox, P. T. (2010). Acute effects of hydrocortisone on the human brain: An fMRI study. Psychoneuroendocrinology, 35(1), 15-20.

Manuck, S. B., Marsland, A. L., Flory, J. D., Gorka, A., Ferrell, R. E., \& Hariri, A. R. (2010). Salivary testosterone and a trinucleotide (CAG) length polymorphism in the androgen receptor gene predict amygdala reactivity in men. Psychoneuroendocrinology, 35(1), 94-104.

Marsh, A. A., Finger, E. C., Mitchell, D. G. V., Reid, M. E., Sims, C., Kosson, D. S., et al. (2008). Reduced amygdala response to fearful expressions in children and adolescents with callousunemotional traits and disruptive behavior disorders. American Journal of Psychiatry, 165, 712-720.

Mehta, P. H., \& Beer, J. (2010). Neural mechanisms of the testosterone-aggression relation: The role of orbitofrontal cortex. Journal of Cognitive Neuroscience, 22(10), 2357-2368.

Mehta, P. H., Jones, A. C., \& Josephs, R. A. (2008). The social endocrinology of dominance: Basal testosterone predicts cortisol changes and behavior following victory and defeat. Journal of Personality and Social Psychology, 94(6), 1078-1093.

Mehta, P. H., \& Josephs, R. A. (2010). Testosterone and cortisol jointly regulate dominance: Evidence for a dual-hormone hypothesis. Hormones and Behavior, 58(5), 898-906.

Nelson, R. J., \& Trainor, B. C. (2007). Neural mechanisms of aggression. Nature reviews. Neuroscience, 8(7), 536-546.

Oei, N. Y., Tollenaar, M. S., Spinhoven, P., \& Elzinga, B. M. (2009). Hydrocortisone reduces emotional distracter interference in working memory. Psychoneuroendocrinology, 34(9), 12841293.

Pajer, K., Tabbah, R., Gardner, W., Rubin, R., Kennethczambel, R., \& Wang, Y. (2006). Adrenal androgen and gonadal hormone levels in adolescent girls with conduct disorder. Psychoneuroendocrinology, 31(10), 1245-1256.

Phelps, E. A., \& LeDoux, J. E. (2005). Contributions of the amygdala to emotion processing: From animal models to human behavior. Neuron, 48(2), 175-187.

Piazza, P. V., \& Le Moal, M. (1997). Glucocorticoids as a biological substrate of reward: Physiological and pathophysiological implications. Brain Research Reviews, 25, 359-372.

Popma, A., Vermeiren, R., Geluk, C., Rinne, T., Vandenbrink, W., Knol, D., et al. (2007). Cortisol moderates the relationship between testosterone and aggression in delinquent male adolescents. Biological Psychiatry, 61(3), 405-411.

Putman, P., Antypa, N., Crysovergi, P., \& van der Does, W. A. (2010a). Exogenous cortisol acutely influences motivated 
decision making in healthy young men. Psychopharmacology, 208(2), 257-263.

Putman, P., Hermans, E. J., Koppeschaar, H., van Schijndel, A., \& van Honk, J. (2007a). A single administration of cortisol acutely reduces preconscious attention for fear in anxious young men. Psychoneuroendocrinology, 32(7), 793-802.

Putman, P., Hermans, E. J., \& van Honk, J. (2004). Emotional stroop performance for masked angry faces: It's BAS, not BIS. Emotion, 4(3), 305-311.

Putman, P., Hermans, E. J., \& van Honk, J. (2007b). Exogenous cortisol shifts a motivated bias from fear to anger in spatial working memory for facial expressions. Psychoneuroendocrinology, 32(1), 14-21.

Putman, P., Hermans, E. J., \& van Honk, J. (2010b). Cortisol administration acutely reduces threat-selective spatial attention in healthy young men. Physiology \& Behavior, 99(3), 294-300.

Raine, A. (1996). Autonomic nervous system factors underlying disinhibited, antisocial, and violent behavior. Annals of the New York Academy of Sciences, 794, 46-59.

Ratka, A., Sutanto, W., Bloemers, M., \& de Kloet, E. R. (1989). On the role of brain mineralocorticoid (type I) and glucocorticoid (type II) receptors in neuroendocrine regulation. Neuroendocrinology, 50(2), 117-123.

Reul, J. M., \& de Kloet, E. R. (1985). Two receptor systems for corticosterone in rat brain: Microdistribution and differential occupation. Endocrinology, 117(6), 2505-2511.

Rosell, D. R., Thompson, J. L., Slifstein, M., Xu, X., Frankle, W. G., New, A. S., et al. (2010). Increased serotonin 2A receptor availability in the orbitofrontal cortex of physically aggressive personality disordered patients. Biological Psychiatry, 67(12), $1154-1162$.

Sarkey, S., Azcoitia, I., Garcia-Segura, L., Garcia-Ovejero, D., \& Doncarlos, L. (2008). Classical androgen receptors in nonclassical sites in the brain. Hormones and Behavior, 53(5), 753-764.

Schulkin, J. (2003). Rethinking homeostasis. Allostatic regulation in physiology and pathophysiology. Cambridge, MA: MIT Press.

Schulkin, J. (2007). Autism and the amygdala: An endocrine hypothesis. Brain and Cognition, 65(1), 87-99.

Schulkin, J., Gold, P. W., \& McEwen, B. (1998). Induction of corticotropin-releasing hormone gene expression by glucocorticoids: Implications for understanding the states of fear and anxiety and allostatic load. Psychoneuroendocrinology, 23(3), 219-243.

Siever, L. J., Buchsbaum, M. S., New, A. S., Spiegel-Cohen, J., Wei, T., Hazlett, E., et al. (1999). d,l-fenfluramine response in impulsive personality disorder assessed with $[18 \mathrm{~F}]$ fluorodeoxyglucose positron emission tomography. Neuropsychopharmacology, 20(5), 413-423.

Soderstrom, H., Blennow, K., Manhem, A., \& Forsman, A. (2001). CSF studies in violent offenders I. 5-HIAA as a negative and HVA as a positive predictor of psychopathy. Journal of Neural Transmission, 108, 869-878.

Taylor, S. P. (1967). Aggressive behavior and physiological arousal as a function of provocation and the tendency to inhibit aggression. Journal of Personality, 35(2), 297-310.

Terburg, D., Hooiveld, N., Aarts, H., Kenemans, J. L., \& van Honk, J. (2011). Eye tracking unconscious face-to-face confrontations: Dominance motives prolong gaze to masked angry faces. Psychological Science, 22(3), 314-319.

Terburg, D., Morgan, B., \& van Honk, J. (2009). The testosteronecortisol ratio: A hormonal marker for proneness to social aggression. International Journal of Law and Psychiatry, 32(4), 216-223.

Tilbrook, A. J., Turner, A. I., \& Clarke, I. J. (2000). Effects of stress on reproduction in non-rodent mammals: The role of glucocorticoids and sex differences. Reviews of Reproduction, $5,105-113$

Trainor, B. C., Kyomen, H. H., \& Marler, C. A. (2006). Estrogenic encounters: how interactions between aromatase and the environment modulate aggression. Frontiers in Neuroendocrinology, 27(2), 170-179.

van Honk, J., Harmon-Jones, E., Morgan, B. E., \& Schutter, D. J. L. G. (2010). Socially explosive minds: The triple imbalance hypothesis of reactive aggression. Journal of Personality, 78(1), 67-94.

van Honk, J., Peper, J. S., \& Schutter, D. J. (2005). Testosterone reduces unconscious fear but not consciously experienced anxiety: Implications for the disorders of fear and anxiety. Biological Psychiatry, 58(3), 218-225.

van Honk, J., Schutter, D. J. L. G., Hermans, E. J., Piutman, P., Tuiten, A., \& Koppeschaar, H. (2004). Testosterone shifts the balance between sensitivity for punishment and reward in healthy young women. Psychoneuroendocrinology, 29(7), 937-943.

van Honk, J., Schutter, D. J. L. G., Hermans, E. J., \& Putman, P. (2003). Low cortisol levels and the balance between punishment sensitivity and reward dependency. Neuroendocrinology, 14(15), 1993-1996.

van Honk, J., Tuiten, A., Hermans, E. J., Putnam, P., Koppeschaar, H., Thijssen, J., et al. (2001). A single administration of testosterone induces cardiac accelerative responses to angry faces in healthy young women. Behavioral Neuroscience, $115(1), 238-242$.

van Honk, J., Tuiten, A., van den Hout, M., Koppeschaar, H., Thijssen, J., de Haan, E., et al. (1998). Baseline salivary cortisol levels and preconscious selective attention for threat: A pilot study. Psychoneuroendocrinology, 23(7), 741-747.

van Honk, J., Tuiten, A., van den Hout, M., Koppeschaar, H., Thijssen, J., de Haan, E., et al. (2000). Conscious and preconscious selective attention to social threat: Different neuroendocrine response patterns. Psychoneuroendocrinology, $25,577-591$.

van Honk, J., Tuiten, A., Verbaten, R., van den Hout, M., Koppeschaar, H., Thijssen, J., et al. (1999). Correlations among salivary testosterone, mood, and selective attention to threat in humans. Hormones and Behavior, 36, 17-24.

van Peer, J. M., Spinhoven, P., \& Roelofs, K. (2010). Psychophysiological evidence for cortisol-induced reduction in early bias for implicit social threat in social phobia. Psychoneuroendocrinology, 35(1), 21-32.

Viau, V. (2002). Functional cross-talk between the hypothalamicpituitary-gonadal and -adrenal axes. Journal of Neuroendocrinology, 14, 506-513.

Virkunnen, M., \& Linnoila, M. (1993). Serotonin in personality disorders with habitual violence and impulsivity. In S. Hodgins (Ed.), Mental disorders and crime (pp. 227-243). Newbury Park, CA: Sage.

Williams, J. M. G., Mathews, A., \& MacLeod, C. (1996). The emotional stroop task and psychopathology. Psychological Bulletin, 120(1), 3-24.

Wirth, M., \& Schultheiss, O. (2007). Basal testosterone moderates responses to anger faces in humans. Physiology \& Behavior, 90(2-3), 496-505.

Wood, R. (2008). Anabolic-androgenic steroid dependence? Insights from animals and humans. Frontiers in Neuroendocrinology, 29(4), 490-506.

Zak, P. J., Kurzban, R., Ahmadi, S., Swerdloff, R. S., Park, J., Efremidze, L., et al. (2009). Testosterone administration decreases generosity in the ultimatum game. PLoS ONE, 4(12), $1-7$. 